\title{
EXISTENCE AND UNIQUENESS THEOREM OF FRACTIONAL DIFFERENTIAL EQUATION USING SADOVISKI FIXED - POINT THEOREM
}

\author{
*Fadhel, F. S. and **Hamed, Z. SH. \\ * Department of Mathematics, Collage of Science, Al-Nahrain University, Baghdad, Iraq. \\ **Department of Mathematics, Collage of Science, Al-Mustansiriyah University, Baghdad, Iraq.
}

\begin{abstract}
:
The main objective of this paper is to state and prove the existence and uniqueness theorem of fractional differential equations using one of the most important theorems in nonlinear functional analysis which is the Sadoviski fixed - point theorem. Here the undertaken differential operator is in the sense of Riemann - Liouville definition of fractional integration.
\end{abstract}

Keywords: Existence and uniqueness theorem, fractional differential equations.

\section{Introduction :}

In opposite to differential equations of integer order in which derivatives depends only on the local behavior of the function. An important type of differential equations which is called (fractional differential equations) where the differentiation is of non - integer order Such type of problems may be considered to have the following form, [2,3]:

$$
\mathrm{y}(\alpha)=\mathrm{F}(\mathrm{x}, \mathrm{y}), \mathrm{y}^{\alpha-\mathrm{k}}\left(\mathrm{x}_{0}\right)=\mathrm{y}_{0},
$$

Where $\mathrm{n}$ is an integer number, $\mathrm{k}=1, \mathrm{n}$, $\mathrm{n}-1 \leq \alpha \leq \mathrm{n}$.

Real life problems with fractional differential equations are of great importance, since fractional differential equations accumulate the whole information of the function in a weighted form . This has many applications in physics, chemistry, engineering, etc., [3]. For that reason, we need a method for solving such equations, effectively, easy to use and applied for different problems.

The main theme of this paper is to state and prove the existence and uniqueness theorem of the above fractional differential equations using Sadoviski fixed-point theorem, [4].

\section{Basic Concepts:}

In this section, some fundamental concepts necessary for this work are introduced.

\subsection{Kuaratowski - Measure of Non Compact of Sets, [4], [7]:}

Let $M$ be a bounded set in a metric space $(X, d)$, then Kuaratowski non compactness measure $\chi$ of $\mathrm{M}$ ( denoted by $\chi(\mathrm{M}))$ is defined to be the infimum of the set of all numbers $\varepsilon>0$ with the property that; $\mathrm{M}$ can be covered by finitely many sets, each of whose diameter is less than or equal to $\varepsilon$. In other words, let $\mathrm{X}$ be a Banach space and $\mathrm{A}$ be a family of bounded sets, then $\chi: \mathrm{A} \longrightarrow$ $\mathrm{R}^{+}$, defined by :

$$
\begin{aligned}
\chi(M)= & \inf \{\varepsilon>0: M \text { admits a finite } \\
& \text { cover by set of diameter } \leq \varepsilon\}
\end{aligned}
$$

The non compactness measure have the following properties [4]:

\section{Remarks (1), [5]:}

Let $\mathrm{X}$ be a Banach space over $\mathrm{R}$ or $\mathrm{C}$. Then for all bounded subsets $M, M_{1}, M_{2}, \ldots, M_{n}$ and $\mathrm{N}$ of $\mathrm{X}$, we have the following results :

1. $\chi(\phi)=0$.

2. $\chi(\mathrm{M})=0$ if and only if $\mathrm{M}$ is relatively compact.

3. $0 \leq \chi(\mathrm{M}) \leq \operatorname{diam}(\mathrm{M})$, where $\operatorname{diam}(\mathrm{M})$ stands for the diameter of $\mathrm{M}$.

4. $\mathrm{M} \subset \mathrm{N}$ implies that $\chi(\mathrm{M}) \leq \chi(\mathrm{N})$.

5. $\chi(\mathrm{M}+\mathrm{N}) \leq \chi(\mathrm{M})+\chi(\mathrm{N})$.

6. $\chi(\beta \mathrm{M})=|\beta| \chi(\mathrm{M})$, for all $\beta \in \mathrm{R}$ or $\mathrm{C}$.

7. $\chi(\mathrm{M})=\chi(\overline{\mathrm{M}})$. 
8. $\chi\left\{\bigcup_{i=1}^{n} M_{i}\right\}=\max \left\{\chi\left(M_{1}\right), \cdots, \chi\left(M_{n}\right)\right\}$.

\subsection{Condensing Mapping [1],[4],[8]:}

Let $\mathrm{T}: \mathrm{D}(\mathrm{T}) \subseteq \mathrm{X} \rightarrow \mathrm{X}$ be an operator over a Banach space $X$. Then $T$ is called a $\mathrm{k}$-set contraction if and only if, there is a number $\mathrm{k} \geq 0$, such that :

$$
\chi(\mathrm{T}(\mathrm{M})) \leq \mathrm{k} \chi(\mathrm{M})
$$

for all bounded subsets $\mathrm{D}(\mathrm{T})$ of the domain $\mathrm{M}$ and $\mathrm{k}$ is called the contractivity factor of $\mathrm{T}$.

Also, $\mathrm{T}$ is called condensing if and only if $\chi(\mathrm{T}(\mathrm{M})) \leq \chi(\mathrm{M})$ for all bounded subset $\mathrm{M}$ of $\mathrm{D}(\mathrm{T})$ with $\chi(\mathrm{M})>0$. It is clear that every $\mathrm{k}$-set contraction with $0 \leq \mathrm{k}<1$ is condensing. The next proposition is given in [4] with out details, we give the proof for completeness.

\section{Proposition (2):}

If $\chi$ is anon compactness measure over a Banach space $\mathrm{X}$, and $\mathrm{T}: \mathrm{D}(\mathrm{T}) \subseteq \mathrm{X} \rightarrow \mathrm{X}$ is any operator, then $\chi(\mathrm{T}(\mathrm{M})) \leq \mathrm{k} \chi(\mathrm{M})$ if and only if $\|\mathrm{Tx}-\mathrm{Ty}\| \leq \mathrm{k}\|\mathrm{x}-\mathrm{y}\|$, for all bounded subsets $M$ of $\mathrm{D}(\mathrm{T})$ and all $\mathrm{x}, \mathrm{y} \in \mathrm{D}(\mathrm{T})$, where $\|$.$\| stands for the$ maximum norm.

\section{Proof :}

Let $\chi: A \rightarrow \mathrm{R}^{+}$, where $\mathrm{A}$ the family of bounded subset of $\mathrm{X}$. By definition of the non-compactness measure, we have:

$$
\begin{aligned}
& \chi(\mathrm{M})= \inf \{\varepsilon>0 \mid \mathrm{M} \text { admits a finite } \\
& \text { cover by sets of diameter } \leq \\
&\varepsilon\}
\end{aligned}
$$

where $\mathrm{M} \in \mathrm{A}$ and $\mathrm{N}_{\mathrm{i}}$ be the cover of $\mathrm{M}$ with $\operatorname{diam} \leq \varepsilon$.

Also, we have :

$$
\operatorname{diam}\left(\mathrm{N}_{\mathrm{i}}\right)=\sup \left\{\mathrm{d}(\mathrm{x}, \mathrm{y}) \mid \mathrm{x}, \mathrm{y} \in \mathrm{N}_{\mathrm{i}}, \mathrm{i}=1, \ldots, \mathrm{n}\right\}
$$

$\sup \left\{d(x, y) \mid x, y \in N_{i}, i=1, \ldots, n\right\} \leq \varepsilon=d\left(x_{i}, y_{i}\right)$

Hence :

$\chi(\mathrm{M})=\inf \left\{\mathrm{d}\left(\mathrm{x}_{\mathrm{i}}, \mathrm{y}_{\mathrm{i}}\right)>0 \mid \mathrm{x}_{\mathrm{i}}, \mathrm{y}_{\mathrm{i}} \in \mathrm{N}_{\mathrm{i}}, \mathrm{i}=1, \ldots, \mathrm{n}\right\}$

Let:

$$
\begin{aligned}
\inf \left\{d\left(x_{i}, y_{i}\right)\right. & \left.>0 \mid x_{i}, y_{i} \in N_{i}, i=1, \ldots, n\right\} \\
& =d\left(x_{i}^{0}, y_{i}^{0}\right)
\end{aligned}
$$

Then

$$
\chi(\mathrm{M})=\mathrm{d}\left(\mathrm{x}_{\mathrm{i}}^{0}, \mathrm{y}_{\mathrm{i}}^{0}\right) \text {, for all } \mathrm{x}_{\mathrm{i}}^{0}, \mathrm{y}_{\mathrm{i}}^{0} \in \mathrm{N}_{\mathrm{i}}
$$

Hence $\chi(T(M))=d\left(T x_{i}^{0}-T_{i}^{0}\right)$

Now if $\|x-y\|=|x-y|$, then:

$$
\begin{aligned}
& \chi(\mathrm{M})=\mathrm{d}\left(\mathrm{x}_{\mathrm{i}}^{0}, \mathrm{y}_{\mathrm{i}}^{0}\right)=\left|\mathrm{x}_{\mathrm{i}}^{0}-\mathrm{y}_{\mathrm{i}}^{0}\right|=\left\|\mathrm{x}_{\mathrm{i}}^{0}-\mathrm{y}_{\mathrm{i}}^{0}\right\| \\
& \begin{aligned}
\chi(\mathrm{T}(\mathrm{M})) & =\mathrm{d}\left(\mathrm{Tx}_{\mathrm{i}}^{0}, \mathrm{Ty}_{\mathrm{i}}^{0}\right) \\
& =\left|\mathrm{Tx}_{\mathrm{i}}^{0}-\mathrm{Ty}_{\mathrm{i}}^{0}\right|=\left\|\mathrm{Tx}_{\mathrm{i}}^{0}-\mathrm{Ty}_{\mathrm{i}}^{0}\right\|
\end{aligned}
\end{aligned}
$$

Therefore $\quad \chi(\mathrm{T}(\mathrm{M})) \leq \mathrm{k} \chi(\mathrm{M}) \quad$ which is equivalent to $\left\|\mathrm{Tx}_{\mathrm{i}}^{0}-\mathrm{Ty}_{\mathrm{i}}^{0}\right\| \leq \mathrm{k}\left\|\mathrm{x}_{\mathrm{i}}^{0}-\mathrm{y}_{\mathrm{i}}^{0}\right\|$.

Now, we are in a position to state Sadoviski fixed-point theorem, which plays an important rule in the next section in the proof of the existence and uniqueness theorem of fractional differential equation.

\subsection{Sadoviski Fixed-Point Theorem, [4]:}

Suppose that:

1. $\mathrm{M}$ is a non empty, closed, bounded and convex subset of Banach space $\mathrm{X}$.

2. The operator $\mathrm{T}: \mathrm{M} \subseteq \mathrm{X} \longrightarrow \mathrm{X}$ is condensing.

Then $\mathrm{T}$ has a fixed point.

\section{Existence of Solutions of Fractional Differential Equation:}

Existence of solutions of fractional differential equations are of great importance in practical applications of fractional differential equations. The statement of the existence theorem is as follows:

\section{Theorem (3):}

Consider the fractional differential equation:

$$
\mathrm{D}^{(\alpha)} \mathrm{y}(\mathrm{x})=\mathrm{F}(\mathrm{x}, \mathrm{y}(\mathrm{x}))
$$

where $y\left(x_{0}\right)=0, \alpha \in(0,1)$, where $D^{(\alpha)}$ represent the fractional derivative in operator form of order $\alpha$ and suppose that $\Omega$ is an open subset of $\square \times \mathrm{C}\left[\mathrm{x}_{0}, \beta\right]$ and $\mathrm{f}: \Omega \rightarrow \mathrm{R}^{\mathrm{n}}$ be a continuous and bounded function, then for any $\left(\mathrm{x}_{0}, 0\right) \in \Omega$, there exist a solution to the fractional differential equation (1) which passes through $\left(\mathrm{x}_{0}, 0\right)$. 


\section{Proof:}

Applying $\mathrm{D}^{-\alpha}$ operator to the both sides of equation (1), gives:

$$
\mathrm{y}(\mathrm{x})=\mathrm{D}^{-\alpha} \mathrm{F}(\mathrm{x}, \mathrm{y}(\mathrm{x})), \mathrm{y}\left(\mathrm{x}_{0}\right)=0
$$

The differential equation (2) may involve Riemann-Liouville formula of fractional order $0<\alpha<1$, which takes the form:

$$
y(x)=\frac{1}{\Gamma(m-\alpha)} \int_{x_{0}}^{x} \frac{F(u, y(u))}{(x-u)^{\alpha-m+1}} d u
$$

which is a singular Volterra integral equation, where $\Gamma(M-\alpha)$ stands for the gamma function and $\mathrm{x} \neq \mathrm{u}$.

Now, let us define the following set:

$$
I_{\beta}=\left\{x \in R: x_{0} \leq x \leq \beta\right\}
$$

where $\beta \in \square$ and suppose that $F$ is a bounded function at $\left(\mathrm{x}_{0}, 0\right)$, that is, there exist a constant $\mathrm{m} \in \square^{+}$, such that:

$$
\left\|\mathrm{F}\left(\mathrm{x}_{0}, 0\right)\right\|_{\infty} \leq \mathrm{m}
$$

where $\|\cdot\|_{\infty}$ stands for the essential bounded norm.

\section{Let:}

$\mathrm{M}=\left\{\mathrm{y}(\mathrm{x}) \in \mathrm{C}\left[\mathrm{x}_{0}, \beta\right]: \mathrm{y}\left(\mathrm{x}_{0}\right)=0\right.$ and $\mathrm{y}(\mathrm{x})$ is bounded $\}$

and define the transformation $\mathrm{T}: \mathrm{C}\left[\mathrm{x}_{0}, \beta\right] \subseteq$ $\mathrm{M} \longrightarrow \mathrm{M}$, as follows:

$$
y(x)= \begin{cases}\frac{1}{\Gamma(m-\alpha)} \int_{x_{0}}^{x} \frac{F(u, y(u))}{(x-u)^{\alpha-m+1}} d u, & x \in I_{\beta}, x \neq u \\ 0, & x=x_{0}\end{cases}
$$

Now, by construction $\mathrm{M}$ is closed, bounded and convex subset of $\left[\mathrm{x}_{0}, \beta\right]$. Also, $\mathrm{M}$ is convex, since if we let $\mathrm{y}_{1}(\mathrm{x}), \mathrm{y}_{2}(\mathrm{x}) \in \mathrm{M}$, then:

$$
\mathrm{y}_{1}(\mathrm{x}) \in \mathrm{C}\left[\mathrm{x}_{0}, \beta\right], \mathrm{y}_{1}\left(\mathrm{x}_{0}\right)=0,
$$

where $C\left[x_{0}, \beta\right]$ stands for the set of continuous function on $\left[\mathrm{x}_{0}, \beta\right]$,

$$
\mathrm{y}_{2}(\mathrm{x}) \in \mathrm{C}\left[\mathrm{x}_{0}, \beta\right] \mathrm{y}_{2}\left(\mathrm{x}_{0}\right)=0
$$

To prove that:

$$
\mathrm{z}(\mathrm{x})=\lambda \mathrm{y}_{1}(\mathrm{x})+(1-\lambda) \mathrm{y}_{2}(\mathrm{x}) \in \mathrm{M},
$$

Where $\lambda \in[0,1], x \in\left[x_{0}, \beta\right]$

so that, $\mathrm{z}(\mathrm{x}) \in \mathrm{C}\left[\mathrm{x}_{0}, \beta\right]$ and $\mathrm{z}\left(\mathrm{x}_{0}\right)=0$.

Since $y_{1}(x), y_{2}(x) \in C\left[x_{0}, \beta\right]$ and the linear combination of continuous functions is also a continuous function, hence [6] :

$$
\mathrm{z}(\mathrm{x}) \in \mathrm{C}\left[\mathrm{x}_{0}, \beta\right]
$$

and also:

$$
\begin{aligned}
\mathrm{z}\left(\mathrm{x}_{0}\right) & =\lambda \mathrm{y}_{1}\left(\mathrm{x}_{0}\right)+(1-\lambda) \mathrm{y}_{2}\left(\mathrm{x}_{0}\right) \\
& =\lambda * 0+(1-\lambda) * 0=0 .
\end{aligned}
$$

hence $z(x) \in M$, such that, $M$ is a convex set.

Moreover, to prove that $\mathrm{T}$ is a condensing map, one can prove $\chi(\mathrm{T}(\mathrm{M})) \leq \mathrm{k} \chi(\mathrm{M})$ (which is from proposition (2)) equivalent to:

$$
\|\mathrm{Tx}-\mathrm{Ty}\|_{\infty} \leq \mathrm{k}\|\mathrm{x}-\mathrm{y}\|_{\infty}
$$

for all bounded subsets $M$ of $D(T)$ and all $\mathrm{x}, \mathrm{y} \in \mathrm{D}(\mathrm{T})$.Now:

$$
\begin{aligned}
& \left\|\mathrm{Ty}_{1}(\mathrm{x})-\mathrm{Ty}_{2}(\mathrm{x})\right\|_{\infty}=\| \frac{1}{\Gamma(\mathrm{m}-\alpha)} \int_{\mathrm{x}_{0}}^{\mathrm{x}} \frac{\mathrm{F}\left(\mathrm{u}, \mathrm{y}_{1}(\mathrm{u})\right)}{(\mathrm{x}-\mathrm{u})^{\alpha-m+1}} \mathrm{du} \\
& \quad-\frac{1}{\Gamma(\mathrm{m}-\alpha)} \int_{\mathrm{x}_{0}}^{\mathrm{x}} \frac{\mathrm{F}\left(\mathrm{u}, \mathrm{y}_{2}(\mathrm{u})\right)}{(\mathrm{x}-\mathrm{u})^{\alpha-\mathrm{m}+1}} \mathrm{du} \|_{\infty} \\
& \quad-\frac{\mathrm{F}\left(\mathrm{u}, \mathrm{y}_{2}(\mathrm{u})\right)}{(\mathrm{x}-\mathrm{u})^{\alpha-m+1}} \int_{\mathrm{x}_{0}}^{\mathrm{x}}\left(\frac { \mathrm { F } ( \mathrm { u } , \mathrm { y } _ { 1 } ( \mathrm { u } ) ) } { ( \mathrm { x } - \mathrm { u } ) ^ { \alpha - \mathrm { m } + 1 } } \left(\mathrm{du} \|_{\infty} \mathrm{du}\right.\right. \\
& \leq \frac{1}{\Gamma(\mathrm{m}-\alpha)} \int_{\mathrm{x}_{0}}^{\mathrm{x}}\left\|\frac{\mathrm{F}\left(\mathrm{u}, \mathrm{y}_{1}(\mathrm{u})\right)-\mathrm{F}\left(\mathrm{u}, \mathrm{y}_{2}(\mathrm{u})\right)}{(\mathrm{x}-\mathrm{u})^{\alpha-\mathrm{m}+1}}\right\|_{\infty} \mathrm{du} \\
& \leq \frac{1}{\Gamma(\mathrm{m}-\alpha)} \int_{\mathrm{x}_{0}}^{\mathrm{x}} \frac{\left\|\mathrm{F}\left(\mathrm{u}, \mathrm{y}_{1}(\mathrm{u})\right)-\mathrm{F}\left(\mathrm{u}, \mathrm{y}_{2}(\mathrm{u})\right)\right\|_{\infty} \mathrm{du}}{\|\mathrm{x}-\mathrm{u}\|_{\infty}^{\alpha-\mathrm{m}+1}} \\
& \quad \forall \mathrm{x} \in\left[\mathrm{x}_{0}, \beta\right], \mathrm{x} \neq \mathrm{u}
\end{aligned}
$$

Since $\mathrm{F}$ is a continuous function on a compact set $\Omega$ which means that it is uniform continuous.

Thus, giving any $\varepsilon>0$, we can find $\delta>0$, such that:

$$
\left|\mathrm{F}\left(\mathrm{u}, \mathrm{y}_{1}(\mathrm{u})\right)-\mathrm{F}\left(\mathrm{u}, \mathrm{y}_{2}(\mathrm{u})\right)\right|<\varepsilon
$$

whenever $\left|\mathrm{y}_{1}-\mathrm{y}_{2}\right|<\delta$.

and letting $\varepsilon=\delta$, then equivalently we can let:

$$
\left|\mathrm{F}\left(\mathrm{u}, \mathrm{y}_{1}(\mathrm{u})\right)-\mathrm{F}\left(\mathrm{u}, \mathrm{y}_{2}(\mathrm{u})\right)\right|<\left|\mathrm{y}_{1}(\mathrm{u})-\mathrm{y}_{2}(\mathrm{u})\right|
$$

hence: 


$$
\begin{aligned}
& \left\|\mathrm{Ty}_{1}(\mathrm{x})-\mathrm{Ty}_{2}(\mathrm{x})\right\|_{\infty} \leq \frac{1}{\Gamma(\mathrm{m}-\alpha)} \\
& \int_{\mathrm{x}_{0}}^{\mathrm{x}} \frac{\left\|\mathrm{y}_{1}(\mathrm{u})-\mathrm{y}_{2}(\mathrm{u})\right\|_{\infty}}{\|(\mathrm{x}-\mathrm{u})\|_{\infty}^{\alpha-\mathrm{m}+1}} \mathrm{du} \\
& \leq \frac{1}{\Gamma(\mathrm{m}-\alpha)}\left\|\mathrm{y}_{1}(\mathrm{u})-\mathrm{y}_{2}(\mathrm{u})\right\|_{\infty} \\
& \sup _{\mathbf{X}_{0} \leq u \leq X} \int_{\mathrm{x}_{0}}^{\mathrm{x}} \frac{1}{\|\mathrm{X}-\mathrm{u}\|_{\infty}^{\alpha-\mathrm{m}+1}} \mathrm{du} \\
& =\frac{\mathrm{c}}{\Gamma(\mathrm{m}-\alpha)}\left\|\mathrm{y}_{1}(\mathrm{u})-\mathrm{y}_{2}(\mathrm{u})\right\|_{\infty} \\
& =\mathrm{k}\left\|\mathrm{y}_{1}(\mathrm{u})-\mathrm{y}_{2}(\mathrm{u})\right\|_{\infty}
\end{aligned}
$$

Thus $\chi(\mathrm{T}(\mathrm{M})) \leq \mathrm{K} \chi(\mathrm{M})$

Hence from Sadoviski fixed point theorem, $\mathrm{T}$ has a fixed point.

Therefore equation (2) has a solution, as well as (1).

\section{Uniqueness Theorem for Fractional Differential Equations:}

Uniqueness is a complementary task to the aspect of existence of solutions in differential equations in general and in fractional differential equation in particular. Therefore, the next theorem discusses the uniqueness of solutions of fractional differential equations.

\section{Theorem (4):}

Let $\Omega$ be an open subset of $\mathrm{R} \times \mathrm{C}\left[\mathrm{x}_{0}, \beta\right]$ and suppose that $\mathrm{f}: \Omega \rightarrow \mathrm{R}^{\mathrm{n}}$ be a continuous function and $\mathrm{F}(\mathrm{x}, 0)$ be Lipschitzian with respect to second argument in every compact subset of $\Omega$. If $\left(x_{0}, 0\right) \in \Omega$, then the fractional differential equation has a unique solution which passes through $\left(\mathrm{x}_{0}, 0\right)$.

\section{Proof :}

Consider $\mathrm{I}_{\beta}=\left\{\mathrm{x} \in \mathrm{R}: \mathrm{x}_{0} \leq \mathrm{x} \leq \beta\right\}$ and let $y_{1}(x), y_{2}(x)$ be two solutions of the fractional differential equation (1) which has an equivalent Volterra functional integral equation on $\left[\mathrm{x}_{0}, \beta\right]$ with $\mathrm{y}_{1}\left(\mathrm{x}_{0}\right)=\mathrm{y}_{2}\left(\mathrm{x}_{0}\right)=0$. Hence:

$$
\begin{aligned}
& \left\|\mathrm{y}_{1}(\mathrm{x})-\mathrm{y}_{2}(\mathrm{x})\right\|_{\infty}=\| \frac{1}{\Gamma(\mathrm{m}-\alpha)} \int_{\mathrm{x}_{0}}^{\mathrm{x}} \frac{\mathrm{F}\left(\mathrm{u}, \mathrm{y}_{1}(\mathrm{u})\right)}{(\mathrm{x}-\mathrm{u})^{\alpha-\mathrm{m}+1}} \mathrm{du}- \\
& \frac{1}{\Gamma(\mathrm{m}-\alpha)} \int_{\mathrm{x}_{0}}^{\mathrm{x}} \frac{\mathrm{F}\left(\mathrm{u}, \mathrm{y}_{2}(\mathrm{u})\right)}{(\mathrm{x}-\mathrm{u})^{\alpha-m+1}} \mathrm{du} \|_{\infty} \\
& =\left\|\frac{1}{\Gamma(m-\alpha)} \int_{x_{0}}^{x}\left(\frac{F\left(u, y_{1}(u)\right)}{(x-u)^{\alpha-m+1}}-\frac{F\left(u, y_{2}(u)\right)}{(x-u)^{\alpha-m+1}}\right) d u\right\|_{\infty} \\
& \leq \frac{1}{\Gamma(m-\alpha)} \int_{x_{0}}^{x}\left\|\frac{F\left(u, y_{1}(u)\right)-F\left(u, y_{2}(u)\right)}{(x-u)^{\alpha-m+1}}\right\|_{\infty} d u \\
& \leq \frac{1}{\Gamma(m-\alpha)} \int_{x_{0}}^{x} \frac{k\left\|y_{1}(u)-y_{2}(u)\right\|_{\infty}}{\|x-u\|_{\infty}^{\alpha-m+1}} d u \\
& \leq \frac{1}{\Gamma(m-\alpha)}\left\|y_{1}(u)-y_{2}(u)\right\|_{\infty} * \sup _{x_{0} \leq u \leq x} \int_{x_{0}}^{x} \frac{1}{\|x-u\|_{\infty}^{\alpha-m+1}} d u \\
& \leq \frac{k \beta c}{\Gamma(m-\alpha)}\left\|y_{1}(u)-y_{2}(u)\right\|_{\infty}
\end{aligned}
$$

we can choose $\frac{\mathrm{k} \beta \mathrm{c}}{\Gamma(\mathrm{m}-\alpha)}<1$ for $\mathrm{x} \in \mathrm{I}_{\beta}$ and should be as small as possible to ensure that:

$$
\frac{\mathrm{k} \beta \mathrm{c}}{\Gamma(\mathrm{m}-\alpha)}\left\|\mathrm{y}_{1}(\mathrm{u})-\mathrm{y}_{2}(\mathrm{u})\right\|_{\infty}<\varepsilon
$$

Hence $\mathrm{y}_{1}(\mathrm{x})=\mathrm{y}_{2}(\mathrm{x}), \forall \mathrm{x} \in \mathrm{I}_{\beta}$.

Thus, there exists a unique solution for fractional differential equation.

\section{Concluding Remarks:}

1. Up to the best of our knowledge, the statement and proof of the existence and uniqueness theorem using Sadoviski fixed point theorem have not been discussed before.

2. We recommend studying new types of equations, which is the so called fuzzy fractional differential equations.

\section{References:}

1. Alsiddiqi, "Functional Analysis With Application", TATA McGraw-Hill Publishing Company Limited, 1986.

2. Al-Adhab, A. A., "Numerical Solutions of Ordinary Fractional Differential Equations", M. Sc. Thesis , College of 
Education (Ibn Al-Haitham), University of Baghdad, 2005.

3. Diethelm K., "Analysis of Fractional Differential Equations", Department of Mathematics, University of Manchester, England, 1999.

4. Eberhard Zeidler, "Nonlinear Functional Analysis and Application Fixed-Point Theorems", Siprenger Verlag, 1986.

5. Erwin Kreyszig, "Introductory Functional Analysis with Applications", John Wiley and Sons, University of Windsor, 1978.

6. Groetsch C.W., "Elements of Applicable Functional Analysis", Marcel Decker Inc., New York and Basel, 1980.

7. Klaus Deimling, "Non linear Functional Analysis", Siprenger Verlag, 1985.

8. Rudin W., "Principles of Mathematical Analysis", $3^{\text {rd }}$ Edition, McGraw-Hill Book Company, 1976.

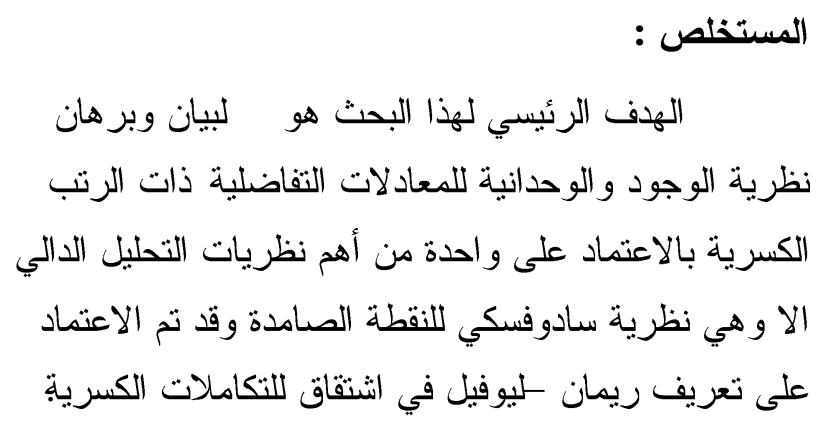

